\title{
Indian agreement with China sets the scene for 1989
}

\section{New Delhi}

IN India, 1988 was seen out with the signing of a new agreement with China on cooperation in science and technology. After having having been cut off from one another for 30 years, scientists of the two countries will now cooperate "on the basis of equality and mutual benefit".

Set alongside increasing technological ties with the Soviet Union - including a promise to aid construction of two nuclear reactors on India's east coast - the agreement may signal a trend for Indian scientists to forge closer ties with colleagues in the communist world. Indo-US cooperation reached a low point in 1988 with dis- putes over patents and protection of intellectual patent property rights.

The five-year science pact with China is one of the three agreements signed during Prime Minister Rajiv Gandhi's preChristmas visit to Beijing. The agreement will provide a framework within which Indian and Chinese institutions can conclude protocols and research contracts. Agriculture and industry will take priority but other forms of technological cooperation may be mutally agreed upon. The agreement also provides for exchange of scientists, documents and journals, and holding of seminars and workshops. From a broader political viewpoint, this agree-

\section{Still no hope of a coherent Australian science policy}

\section{Sydney}

Aт the end of 1988, Australian scientists finally found their voices. Dissatisfaction over reduced funding and the constant calls by the government to make science more commercial angered scientists sufficiently for them to reject the label of "wimps" given by Minister of Science Barry Jones and come out of their laboratories and protest.

Hopes had been raised that a coherent long-term science policy would emerge from the reports of a government interdepartmental committee (IDC) set up to look into funding and policy needs and from the Smith committee investigating university research requirements, even though the former contains no members from the scientific community.

But scientists seem likely to be further disappointed. The IDC report was presented to the cabinet in December and, although it has not yet been made public, details of its recommendations are known. The report acknowledges the problems of Australian science: poor funding, increasing student-to-staff ratios and the reduction in graduate students, but warns that any general topping-up of funds might be interpreted as "too little too late ... The Government (would be seen to be) wavering in its policy directions".

In response to criticism that the administration of science is too fragmented, the report recommends a permanent committee of senior bureaucrats reporting to the Minister of Science to coordinate policy and funding. A "distinguished scientist" would also be appointed for a two-year term as Chief Science Adviser to the minister.

The IDC report allocates A $\$ 20$ million to meet the most urgent needs for labora- tory equipment in the year ending June 1989. But the funds cannot be given out until the Smith committee reports in late March 1989. The amount is much less than that requested by scientists. CSIRO alone requested an extra $\mathrm{A} \$ 75$ million for next year.

The government seems relentless. A spokesperson for Senator John Button, the Minister for Industry, Technology and Commerce said "we are trying to force scientists to get funding from the private sector. Historically scientists go away and set their own priorities. They will just have to get used to living in the real world."

But big business may not be interested. Dr Max Whitton, chief of entomology at CSIRO, said "science cannot attract commercial funding if there isn't the viable operating base to attract partners". Professor David Penington, vice chancellor of the University of Melbourne, agrees. "Industry keeps its distance from us rather than developing a vigorous partnership. The idea that this could be resolved through a directive from Canberra is nonsense. Incentives and deregulation are needed."

Australia's scientists are fearful that in 1989 the downward spiral for research funding will continue. The Federation of Australian Scientific and Technological Societies (FASTS) with 60,000 members is determined to have science funding put on the political agenda, particularly with a federal election likely at the end of the year. Professor Frank Larkins, president of FASTS, said: "Fundamental science is the foundation of applied science.

"If the government wants science and technology to pay economic dividends, we need increased funding and a five- to tenyear policy." ment and two others on culture and trade are seen as a prelude to an accord on the contentious border issue.

Earlier in 1988, India's success with its first remote-sensing satellite (IRS-1) was offset by the failure of the ASLV-3 launcher and the trouble with communications satellite INSAT 1-C.

India's ambitious space programme hinges on the next flight of ASLV-3 and the May 1989 launching of INSAT-1D. The heavy launch vehicle programme could even be terminated if India decides to concentrate instead on the hyperplane, the Defence Department idea for a spaceplane that collects oxygen fuel in flight. Soviet help has been sought.

Indian scientists scored a success with their first low-cost parallel-processing computer and by predicting accurately the behaviour of the monsoon for the first time since the creation of the meteorological department. The government will now launch a three-year project to build a supercomputer.

In the medical field, the birth control vaccine developed by the National Institute of Immunology will enter phase-two trials this year. Another vaccine for sterilizing stray dogs and unproductive cattle has been developed by the same institute and is now for sale.

Materials science, biotechnology and energy are key areas for funding in 1989. The first wave-power plant is being built on the southern coast and a plant is to be set up in Gujarat to extract gas from coal without mining. One nuclear plant will be commissioned in 1989 and 20 more will be built over the next 11 years. The Department of Atomic Energy will have no problems with funds but will find it increasingly difficult to overcome opposition from environmentalists.

On the science policy front, Gandhi has still not acted on his advisers' suggestion for a national commission to integrate science and technology with economic planning. Two controversial decisions on liberalizing seed import and permitting entry of Pepsico in the beverage market have been blamed on the lack of a welldefined technology import policy.

Gandhi has asked scientists to help solve India's problems through technology missions. Telecommunications has provided the first success. India has built its own electronic telephone exchange for cities and the mission intends to supply one exchange every day to rural areas. Over the next few years, backing will be given to missions for drinking water, immunization, cattle improvement and mosquito control. But as yet there is no mission to relieve the sufferings of the thousands of Bhopal gas victims who observed the fourth anniversary of the tragedy on 3 December by burning effigies in front of the Union Carbide factory.

K.S. Jayaraman 